\title{
Evaluation and Comparison of Three Chemical Agents with a New Herbal Agent for Disinfection of Gutta-percha Cones: An in vitro Study
}

\author{
${ }^{1}$ Shabeer Ummer, ${ }^{2}$ Prasanth Dhanapal, ${ }^{3}$ Liza George, ${ }^{4} \mathrm{KM}$ Charlie, ${ }^{5}$ Asha Joseph
}

\section{ABSTRACT}

Aims: To evaluate the effectiveness of grape seed extract (GSE) as a gutta-percha disinfectant and to compare the efficacy with $5 \%$ sodium hypochlorite, $2.5 \%$ sodium hypochlorite, and $2 \%$ chlorhexidine against Bacillus subtilis.

Materials and methods: Minimum inhibitory concentration and minimum bactericidal concentration of GSE were calculated by serial dilution and well-diffusion method. Five hundred gutta-percha cones of ISO size 25 were divided into 10 equal groups $(n=50)$. The 10 groups of gutta-percha cones were inoculated with cultured Bacillus species and incubated for 72 hours for allowing bacterial growth. Each group was then treated with the test solutions for 1 and 5 minutes. The treated groups of gutta-percha cones were then incubated in brain heart infusion agar allowing for bacterial growth, which were later analyzed by the turbidity of the medium. The results were statistically analyzed.

Results: Gutta-percha cones when treated with $2 \%$ chlorhexidine gluconate for 1 and 5 minutes showed the most inhibiting activity against $B$. subtilis. Grape seed extract was found to have limited activity against $B$. subtilis in both 1 - and 5 -minute interval. Both concentrations of $\mathrm{NaOCl}, 2.5$ and $5 \%$, showed reduced activity against $B$. subtilis.

Conclusion: Grape seed extract though has antibacterial activity, when used as gutta-percha disinfectant, was found to be less effective than chlorhexidine gluconate against $B$. subtilis.

Clinical significance: Different methods of gutta-percha cone disinfection have been advocated and GSE for gutta-percha cone disinfection was attempted owing to its herbal antibacterial nature.

Keywords: Bacillus subtilis, Grape seed extract, Gutta-percha cones.

How to cite this article: Ummer S, Dhanapal P, George L, Charlie KM, Joseph A. Evaluation and Comparison of Three Chemical Agents with a New Herbal Agent for Disinfection of Gutta-percha Cones: An in vitro Study. Cons Dent Endod J 2016;1(2):33-37.

\footnotetext{
${ }^{1}$ Postgraduate Student, ${ }^{2}$ Professor, ${ }^{3}$ Professor and Head ${ }^{4}$ Reader, ${ }^{5}$ Senior Lecturer

${ }^{1-5}$ Department of Conservative Dentistry and Endodontics Annoor Dental College, Ernakulam, Kerala, India
}

Corresponding Author: Shabeer Ummer, Postgraduate Student, Department of Conservative Dentistry and Endodontics Annoor Dental College, Ernakulam, Kerala, India, Phone: +919447411539, e-mail: shabeerummertk@yahoo.com

\section{Source of support: Nil}

Conflict of interest: None

\section{INTRODUCTION}

Success of endodontic therapy greatly depends on adherence to aseptic procedures being followed. ${ }^{1}$ For optimum infection control, every instrument and material placed within root canals should be sterile. Gutta-percha is the most commonly used obturating material. Although gutta-percha cones are manufactured under aseptic conditions, contamination during storage or by aerosol during the clinical procedure or handling mandates the need for its disinfection prior to placement in the canal. ${ }^{2}$ Contamination of the cones has been reported to contribute to endodontic failure. ${ }^{2}$

Bacterial contamination has been reported in freshly opened boxes of gutta-percha. ${ }^{2}$ Owing to their physical and chemical nature, gutta-percha cones are not amenable to physical methods of sterilization like hot air oven and autoclaving, necessitating a rapid chair-side disinfection of the cones by using chemical solutions. Sodium hypochlorite in varying concentrations ranging from 0.5 to $5.25 \%$ has been tried for disinfecting gutta-percha cones..$^{3-5}$ Chlorhexidine gluconate, another broad spectrum antimicrobial agent with substantivity and relatively low toxicity, has also reported acceptable levels of disinfection of gutta-percha cones. ${ }^{3-5}$ Sodium hypochlorite and chlorhexidine have been found to make some topographic changes on the surface of gutta-percha cones which may compromise the obturation seal. ${ }^{6,7}$

The aim of this study was to evaluate the effectiveness of grape seed extract (GSE) as a gutta-percha disinfectant and compare the effectiveness with $5 \%$ sodium hypochlorite, $2.5 \%$ sodium hypochlorite, and $2 \%$ chlorhexidine gluconate against Bacillus subtilis at different time intervals of 1 and 5 minutes.

\section{MATERIALS AND METHODS}

Five hundred gutta-percha cones (Dentsply, Maillefer, ISO size 25) were selected and divided into 10 equal groups $(\mathrm{n}=50)$ (Fig. 1). The 10 groups of gutta-percha cones were inoculated with cultured B. subtilis and incubated for 72 hours to allow for bacterial growth (Fig. 2). 


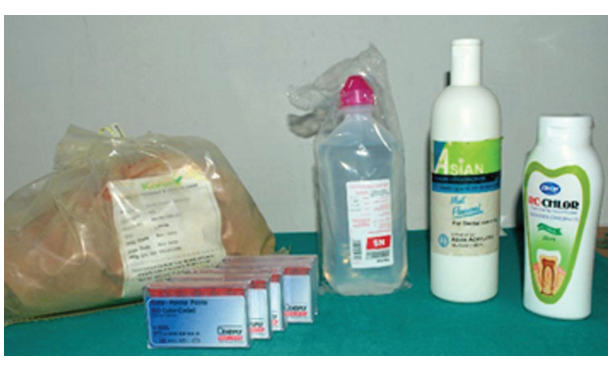

Fig. 1: Materials used

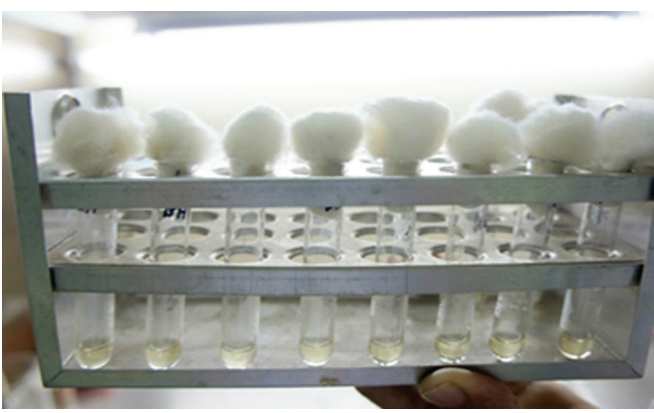

Fig. 3: Serial dilution for MBC

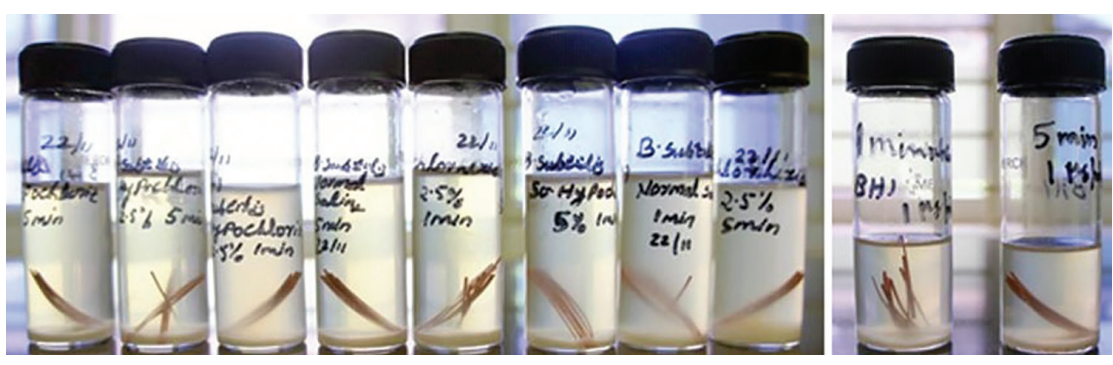

Fig. 2: Gutta-percha cones inoculated with cultured Bacillus subtilis
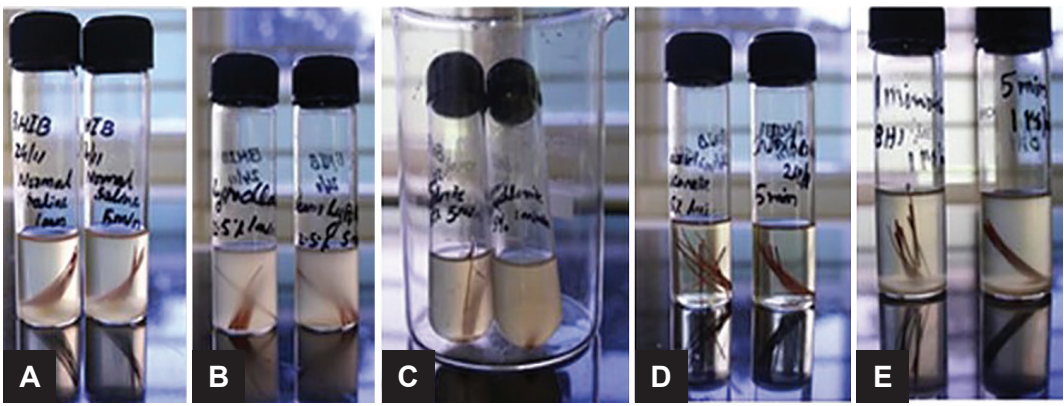

Figs 4A to E: Gutta-percha cones treated with different test solutions: (A) Normal saline; (B) $2.5 \% \mathrm{NaOCl}$; (C) GSE; (D) $5 \% \mathrm{NaOCl}$; and (E) $2 \% \mathrm{CHX}$
Minimum inhibitory concentration (MIC) and minimum bactericidal concentration (MBC) of GSE (Konark Herbals and Health Care, Mumbai) were calculated by serial dilution and was found to be as follows: MIC value: $1 \mu \mathrm{g} / \mathrm{dL}$ and MBC value: $0.5 \mu \mathrm{g} / \mathrm{dL}$ (Fig. 3). $2.5 \%$ of sodium hypochlorite was prepared by diluting commercially available $5 \%$ sodium hypochlorite (Asian, Asian Acrylates, Mumbai) and 2\% chlorhexidine gluconate was sourced from Deor (RC Chlor, Azure Laboratories Pvt. Ltd., Kochi).

The gutta-percha cones allowed for bacterial growth were then treated with the test solutions in the following order (Figs $4 \mathrm{~A}$ to $\mathrm{E})$ :

Group 1: Normal saline for 1 minute
Group 2: Normal saline for 5 minutes

Group 3: 2.5\% Sodium hypochlorite for 1 minute

Group 4: $2.5 \%$ Sodium hypochlorite for 5 minutes

Group 5: 5\% Sodium hypochlorite for 1 minute

Group 6: 5\% Sodium hypochlorite for 5 minutes

Group 7: 2\% Chlorhexidine for 1 minute

Group 8: 2\% Chlorhexidine for 5 minutes

Group 9: GSE for 1 minute

Group 10: GSE for 5 minutes.

The treated groups were then incubated for 48 hours in brain heart infusion (BHI) agar allowing for bacterial growth, which were later analyzed by the turbidity of the medium. Further subcultures were made from the treated solutions to find colony forming units (Figs 5A to E).
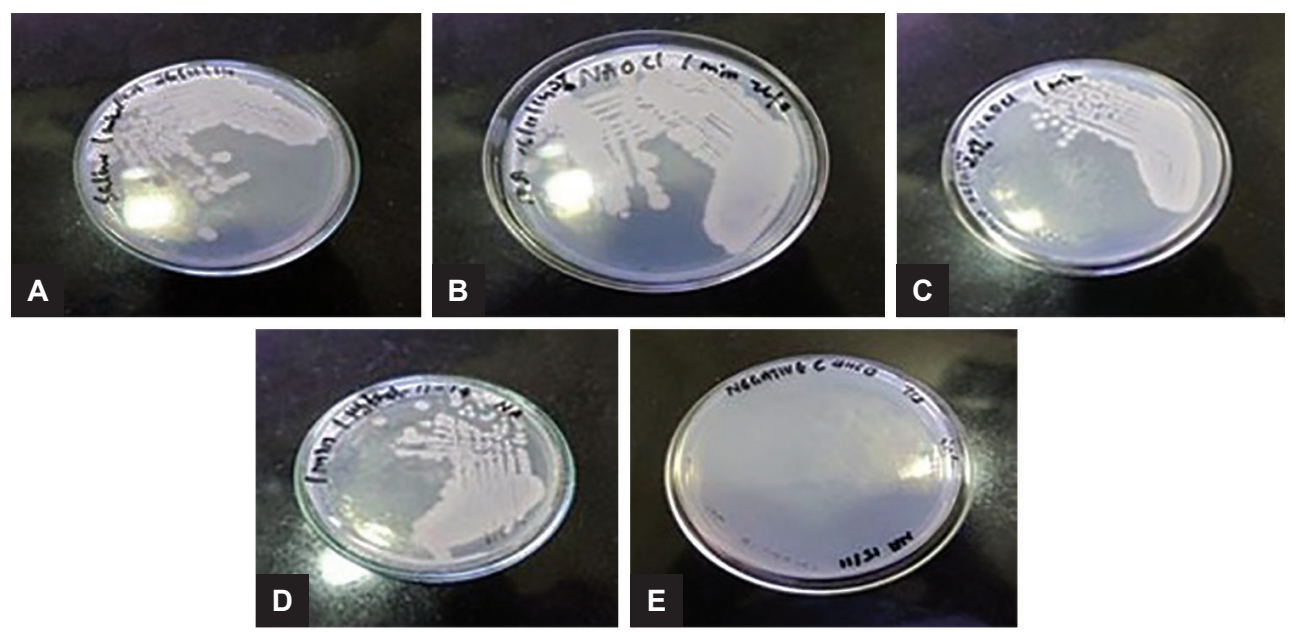

Figs 5A to E: Culture plates with CFUs after incubation (after 5-minute treatment): (A) Normal saline; (B) $5 \% \mathrm{NaOCl}$; (C) $2.5 \% \mathrm{NaOCl}$; (D) GSE; and (E) $2 \% \mathrm{CHX}$ 


\begin{tabular}{lllllll}
\hline & \multicolumn{3}{l}{ Table 1: Descriptive statistics } & & \\
\hline & & $N$ & Mean & Std. deviation & Minimum & Maximum \\
\hline 1 Minute & Normal saline & 6 & 1.9500 & 0.10488 & 1.80 & 2.10 \\
& 2.5\% Sodium hypochlorite & 6 & 2.0250 & 0.15411 & 1.90 & 2.30 \\
& 5\% Sodium hypochlorite & 6 & 4.0667 & 0.09832 & 3.95 & 4.20 \\
& 2\% Chlorhexidine & 6 & .0867 & 0.04033 & 0.05 & 0.15 \\
& Grape seed extract & 6 & 2.3500 & 0.10488 & 2.20 & 2.50 \\
& Total & 30 & 2.0957 & 1.29130 & 0.05 & 4.20 \\
& Normal saline & 6 & 2.1000 & 0.20976 & 1.90 & 2.40 \\
& 2.5\% Sodium hypochlorite & 6 & 2.0100 & 0.12506 & 1.89 & 2.25 \\
& 5\% Sodium hypochlorite & 6 & 4.1683 & 0.17034 & 4.00 & 4.40 \\
& 2\% Chlorhexidine & 6 & .1883 & 0.03971 & 0.15 & 0.25 \\
& Grape seed extract & 6 & 2.4833 & 0.11690 & 2.30 & 2.60 \\
& Total & 30 & 2.1900 & 1.29723 & 0.15 & 4.40 \\
\hline
\end{tabular}

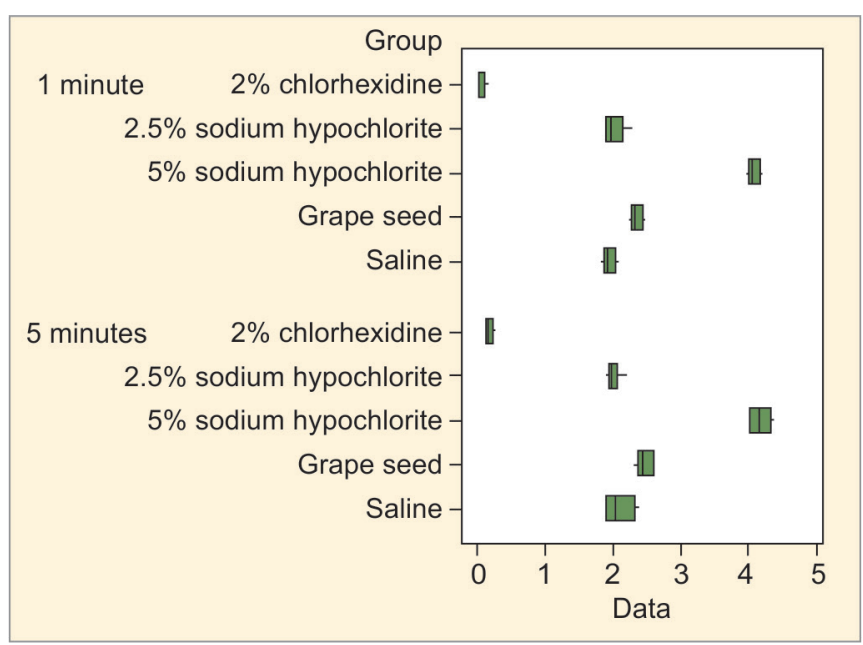

Graph 1: Box plot of bacterial count at 1 and 5 minutes

\section{RESULTS}

The descriptive statistics of different groups are tabulated in Table 1 and it can be observed that the mean bacterial count at 1 minute time point is maximum in group 5 followed by groups $9,3,1$, and 7 . The mean bacterial count at 5 -minute time point is maximum in group 6 followed by groups $10,2,4$, and 8 .

The Box plot at 1 and 5 minutes showed that bacterial count is maximum for groups 3 and 4 and minimum for groups 7 and 8 (Graph 1).

From the analysis of variance (ANOVA) table it was observed that bacterial count is significantly different in each group (Table 2).

Tukey's post hoc analysis also showed significant difference between all the groups except normal saline and $2.5 \%$ sodium hypochlorite (Table 3 ). From the paired t-test it can be observed that there is no difference in mean bacterial count at different time points -1 and 5 minutes for the study group - Grape Seed Extract (Table 4).
Table 2: One-way ANOVA

\begin{tabular}{llllll}
\hline & $\begin{array}{l}\text { Sum of } \\
\text { squares }\end{array}$ & $d f$ & Mean square & $F$ & $p$-value \\
\hline $\begin{array}{l}\text { Between } \\
\text { groups }\end{array}$ & 48.071 & 4 & 12.018 & 1053.386 & 0.000 \\
$\begin{array}{l}\text { Within } \\
\text { groups }\end{array}$ & 0.285 & 25 & 0.011 & & \\
\hline Total & 48.356 & 29 & & & \\
\hline
\end{tabular}

\section{DISCUSSION}

Bacillus subtilis was used in this study, since it is a common clinical pathogen and a major organism used to find the effectiveness of various sterilization protocols. ${ }^{8}$ Gutta-percha points are contaminated by variety of organisms, such as cocci, rods, yeasts, or by contact with objects once they are exposed to dental chair-side clinical environment. ${ }^{9}$ Sodium hypochlorite, though a proven gutta-percha disinfectant, both 2.5 and $5 \%$ concentrations, used in this study did not completely inhibit the growth of B. subtilis in BHI agar. ${ }^{10-12}$ The reduced activity of sodium hypochlorite could be due to the presence of the culture medium being used, i.e., BHI agar, or the sodium hypochlorite solution selected for the study was not freshly prepared, instead commercially available sources were selected.

Two percent Chlorhexidine gluconate, which is another commonly available disinfectant well documented for its broad spectrum of antimicrobial activity and substantivity property when used for both 1 and 5 minutes, was found to have antibacterial activity against $B$. subtilis which is in accordance with previous literature. ${ }^{13}$

Grape (Vitis vinifera) seeds are considered rich sources of polyphenolic compounds, like monomeric catechin and epicatechin, gallic acid, and polymeric and oligomeric procyanidins. ${ }^{14}$ Grape phenolics are molecules of hydroquinone, pyrocatechol, caffeic acid, ferulic acid, p-coumaric acid, gallic acid, ellagic acid, 
Table 3: Tukey's post hoc test

\begin{tabular}{|c|c|c|c|c|}
\hline (I) Group & (J) Group & Mean difference (I-J) & Std. error & $p$-value \\
\hline \multirow[t]{4}{*}{ Normal saline } & $2.5 \%$ Sodium hypochlorite & -0.07500 & 0.06167 & 0.742 \\
\hline & $5 \%$ Sodium hypochlorite & -2.11667 & 0.06167 & 0.000 \\
\hline & 2\% Chlorhexidine & 1.86333 & 0.06167 & 0.000 \\
\hline & Grape seed extract & -0.40000 & 0.06167 & 0.000 \\
\hline \multirow[t]{4}{*}{$2.5 \%$ Sodium hypochlorite } & Normal saline & 0.07500 & 0.06167 & 0.742 \\
\hline & $5 \%$ Sodium hypochlorite & -2.04167 & 0.06167 & 0.000 \\
\hline & $2 \%$ Chlorhexidine & 1.93833 & 0.06167 & 0.000 \\
\hline & Grape seed extract & -0.32500 & 0.06167 & 0.000 \\
\hline \multirow[t]{4}{*}{$5 \%$ Sodium hypochlorite } & Normal Saline & 2.11667 & 0.06167 & 0.000 \\
\hline & $2.5 \%$ Sodium hypochlorite & 2.04167 & 0.06167 & 0.000 \\
\hline & $2 \%$ Chlorhexidine & 3.98000 & 0.06167 & 0.000 \\
\hline & Grape seed extract & 1.71667 & 0.06167 & 0.000 \\
\hline \multirow[t]{4}{*}{$2 \%$ Chlorhexidine } & Normal saline & -1.86333 & 0.06167 & 0.000 \\
\hline & $2.5 \%$ Sodium hypochlorite & -1.93833 & 0.06167 & 0.000 \\
\hline & $5 \%$ Sodium hypochlorite & -3.98000 & 0.06167 & 0.000 \\
\hline & Grape seed extract & -2.26333 & 0.06167 & 0.000 \\
\hline \multirow[t]{4}{*}{ Grape seed extract } & Normal saline & 0.40000 & 0.06167 & 0.000 \\
\hline & $2.5 \%$ Sodium hypochlorite & 0.32500 & 0.06167 & 0.000 \\
\hline & $5 \%$ Sodium hypochlorite & -1.71667 & 0.06167 & 0.000 \\
\hline & $2 \%$ Chlorhexidine & 2.26333 & 0.06167 & 0.000 \\
\hline
\end{tabular}

Table 4: Paired t-test

\begin{tabular}{|c|c|c|c|c|c|c|c|}
\hline \multirow[b]{2}{*}{ Group } & & \multicolumn{3}{|c|}{ Paired differences } & \multirow[b]{2}{*}{$t$} & \multirow[b]{2}{*}{$d f$} & \\
\hline & & Mean & $\begin{array}{l}\text { Std. } \\
\text { deviation }\end{array}$ & $\begin{array}{l}\text { Std. } \\
\text { error } \\
\text { mean }\end{array}$ & & & $p$-value \\
\hline GSE & $\begin{array}{l}1-5 \\
\text { minutes }\end{array}$ & -0.13333 & 0.16330 & 0.06667 & -2.000 & 5 & 0.102 \\
\hline
\end{tabular}

and resveratrol. ${ }^{15}$ Grape seed extract is a rich source of diverse bioflavonoids, collectively known as grape seed proanthocyanidins extract. ${ }^{16}$ Polyphenols are well documented to have microbicidal activities against a huge number of pathogenic bacteria. ${ }^{17}$ Grape seed extract has exhibited promising antibacterial properties for dental use without exerting an influence on the biological equilibrium in the oral cavity. Grape seed extract though have antibacterial activity, it was never tried as a guttapercha disinfectant to the best of knowledge. In this study, GSE when used for both 1 and 5 minutes was found to have limited activity against B. subtilis. Grape seed extract used in this study was procured from commercially available outlet and not freshly prepared. Freshly prepared extract may give a better result, which could be attributed to the reduced efficacy.

\section{INFERENCE}

From this study it was inferred that among the test solutions used, $2 \%$ chlorhexidine proved to have better as a disinfectant against $B$. subtilis, which is in accordance with earlier studies by Cardoso et al. ${ }^{18}$
Also both 2.5 and 5\% concentrations of sodium hypochlorite used in this study did not completely inhibit the growth of B. subtilis in BHI agar.

The herbal antibacterial agent GSE when used for both 1 and 5 minutes was found to have limited activity against $B$. subtilis and there was no significant difference between the two time periods.

\section{CONCLUSION}

Within the limitations of this study, it was concluded that GSE though has antibacterial activity, when used as gutta-percha disinfectant was found to be less effective than chlorhexidine gluconate against $B$. subtilis.

\section{CLINICAL SIGNIFICANCE}

Grape seed extract can be used as an alternative to chemical disinfection of gutta-percha cones but was found to be less effective than chlorhexidine.

\section{REFERENCES}

1. Hurtt CA, Rossman LE. The sterilization of endodontic hand files. J Endod 1996 Jun;22(6):321-322.

2. Namazikhah MS, Sullivan DM, Trnavsky GL. Gutta-percha: a look at the need for sterilization. J Calif Dent Assoc 2000 Jun;28(6):427-432.

3. Gomes BP, Vianna ME, Matsumoto CU, Rossi Vde P, Zaia AA, Ferraz CC. Disinfection of gutta-percha cones with chlorhexidine and sodium hypochlorite. Oral Surg Oral Med Oral Pathol Oral Radiol Endod 2005 Oct;100(4):512-517.

4. Zand V, Salem-Milani A, Shahi S, Akhi MT, Vazifekhah S. Efficacy of different concentrations of sodium hypochlorite 
and chlorhexidine in disinfection of contaminated Resilon cones. Med Oral Patol Oral Cir Buccal 2012 Mar 1;17(2):e352-e355.

5. Pradeep K, Kidiyoor KH, Jain P, Rao N. Chair side disinfection of gutta-percha points - An in vitro comparative study between 5 different agents at different concentrations. Endodontology 2013 Jun;25:73.

6. Pang NS, Jung IY, Bae KS, Baek SH, Lee WC, Kum KY. Effects of short-term chemical disinfection of gutta-percha cones: identification of affected microbes and alterations in surface texture and physical properties. J Endod 2007 May;33(5):594-598.

7. Seabra Pereira OL, Siqueira JF Jr. Contamination of gutta-percha and Resilon cones taken directly from the manufacturer. Clin Oral Investig 2010 Jun;14(3):327-330.

8. Siqueira JF Jr, da Silva CH, Cerqueira M das D, Lopes HP, de Uzeda M. Effectiveness of four chemical solutions in eliminating Bacillus subtilis spores on gutta-percha cones. Endod Dent Traumatol 1998 Jun;14(3):124-126.

9. Linke $\mathrm{HAB}, \mathrm{Chohayeb} A \mathrm{~A}$. Effective surface sterilization of gutta-percha points. Oral Surg Oral Med Oral Pathol 1983 Jan;55(1):73-77.

10. Cardoso C,Kotaka C, Redmerski R, Guilhermetti M, QueirozAF. Rapid decontamination of gutta-percha cones with sodium hypochlorite. J Endod 1999 Jul;25(7):498-501.

11. Ozalp N, Okte Z, Ozcelik B. The rapid sterilization of guttapercha cones with sodium hypochlorite and glutaraldehyde. J Endod 2006 Dec;32(12):1202-1204.
12. de Souza RE, de Souza EA, Sousa-Neto MD, Pietro RC. In vitro evaluation of different chemical agents for the decontamination of gutta-percha cones. Pesqui Odontol Bras 2003 Jan-Mar;17(1):75-77.

13. Redmerski R, Bulla JR, Moreno T, GarciaI LB, Cardoso C. Disinfection of gutta-percha cones with chlorhexidine. Braz J Microbiol 2007 Oct-Dec;38(4):649-655.

14. Monagas M, Gomez-Cordoves C, Bartolome B, Laureano O, Ricardo da Silva JM. Monomeric, oligomeric, and polymeric flavan-3-ol composition of wines and grapes from Vitis vinifera L. Cv. Graciano, Tempranillo, and Cabernet Sauvignon. J Agric Food Chem 2003 Oct;51(22):6475-6481.

15. Jayaprakasha GK, Selvi T, Sakariah KK. Antibacterial and antioxidant activities of grape (Vitis vinifera) seed extracts. Food Res Int 2003;36:117-122.

16. Nakamura Y, Tsuji S, Tonogai Y. Analysis of proanthocyanidins in grape seed extracts, health foods and grape seed oils. J Health Sci 2003;49(1):45-54.

17. Karou D, Dicko MH, Simpore J, Traore AS. Antioxidant and antibacterial activities of polyphenols from ethnomedicinal plants of Burkina Faso. Afr J Biotechnol 2005;4(8):823-828.

18. Cardoso CL, Redmerski R, Bittencourt NLR, Kotaka CR. Effectiveness of different chemical agents in rapid decontamination of guttapercha cones. Braz J Microbiol 2000 Jan-Mar;31(1):67-71. 